\title{
ASPECTOS DESTACADOS DA TEORIA DO ESTADO DE HERMANN HELLER
}

\section{ASPECTOS DESTACADOS DE LA TEORÍA DEL ESTADO DE HERMANN HELLER}

\author{
Cesar Luiz Pasold ${ }^{1}$
}

Licença CC BY:

Artigo distribuído sob os termos Creative Commons, permite uso e distribuição irrestrita em qualquer meio desde que $o$ autor credite a fonte original.

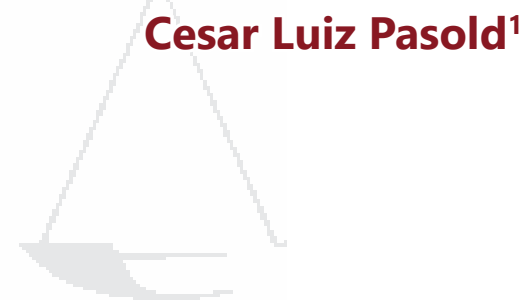

Resumo:A pesquisa, cujos resultados são aqui relatados, possui por Objeto identificar o núcleo da Teoria do Estado concebida por Hermann Heller. E os seus Objetivos, para tanto, são estes: (1) a descrição dos fundamentos e da concepção nuclear da referida Teoria por meio das categorias nucleares do pensamento helleriano, expresso em duas obras de sua autoria; e (2) contribuir para a divulgação deste precioso material da epistemologia estatal de Heller, evidenciando a sua atualidade muito consistente. Para buscar esse desiderato, realizou-se uma Pesquisa Científica, em cuja fase de investigação operou-se com o Método Dedutivo, eis que se partiu da premissa da existência efetiva de uma consistente Teoria de Estado proposta por Heller. Na fase de análise de dados, utilizou-se o Método Analítico. No relatório dos resultados, trabalhase com o Método Indutivo. As Técnicas utilizadas nas fases referidas foram: Técnica do Referente, da Categoria, do Conceito Operacional e da Pesquisa Bibliográfica.

Palavras-chave: Aspectos Destacados; Teoria do Estado; Hermann Heller.

Abstract: The study reported here aims to identify the nucleus of the Theory of the State, as conceived by Hermann Heller. Its objectives are: (1) to describe the bases and the nuclear conception of this Theory through the nuclear categories of Heller's thought, expressed in two works of his authorship and; (2) to contribute to the dissemination of this precious material from Heller's state epistemology, highlighting its very consistent topicality. For this purpose, Scientific Research was carried out in which the investigation phase was operated with the Deductive Method, as it started from the premise of the effective existence of a consistent Theory of State, as proposed by Heller. In the data analysis phase, the Analytical Method was used and in the report of the results, the Inductive method was used. The techniques of Referent Technique, Category, Operational Concept and Bibliographic Research were used in the aforementioned phases.

$1 \quad$ Doutor em Direito do Estado pela USP. Pós-Doutor em Direito das Relações Sociais pela UFPR. Mestre em Saúde Pública pela USP. Mestre em Instituições Jurídicas e Políticas pela UFSC. Doutor Honoris Causa pela UNIVALI. Professor de Teoria do Estado e da Constituição no Curso de Doutorado do Programa de Pós-Graduação Stricto Sensu da UNIVALI, no qual atua nas Linhas de Pesquisa: "Meio Ambiente e Sustentabilidade" e "Principiologia Constitucional e Produção do Direito". Ex-professor nos Cursos de Mestrado e Doutorado em Direito da UFSC nas disciplinas: Teoria Política e Teoria do Estado Contemporâneo. Autor de diversas obras, entre as quais se destacam: Função Social do Estado Contemporâneo. 4.ed. rev. amp. Itajaí/SC: UNIVALI, 2013. E-book http://siaiapp28.univali.br/LstFree.aspx - disponível gratuitamente. Coorganizador e coautor de: SANTO, Davi do; PASOLD, Cesar (Orgs.). Reflexões sobre Teoria da Constituição e do Estado. Florianópolis: Insular, 2013. Organizador e coautor de: Primeiros Ensaios de Teoria do Estado e da Constituição. Curitiba: Juruá, 2010. 
Keywords: Key aspects; Theory of State; Hermann Heller.

Resumen: La investigación, cuyos resultados son aquí relatados, posee por Objeto identificar el núcleo de la Teoría del Estado concebido por Hermann Heller. Y sus Objetivos, para tanto, son estos: (1) la descripción de los fundamentos y de la concepción nuclear de la referida Teoría por medio de las categorías nucleares del pensamiento helleriano, expreso en dos obras de su autoría; y (2) contribuir para la divulgación de este precioso material de la epistemología estatal de Heller, evidenciando su actualidad muy consistente. Para buscar este objetivo, se realizó una Investigación Científica, en cuya fase de investigación se operó con el Método Deductivo, se partió de la premisa de la existencia efectiva de una consistente Teoría de Estado propuesta por Heller. En la fase de análisis de datos, se utilizó el Método Analítico. En el relatório de los resultados, se trabajo con el Método Inductivo. Las Técnicas utilizadas en las fases referidas fueron: Técnica del Referente, de la Categoría, del Concepto Operacional y de la Investigación Bibliográfica.

Palabras clave: Aspectos Destacados; Teoría del Estado; Hermann Heller.

\section{INTRODUÇÃO}

O jurista alemão Hermann Heller construiu uma muito especial Teoria do Estado, sob suas perspectivas como Cientista Político e pesquisador competente, valorizador da Sociologia Política, da História e da Teoria Política Clássica e Moderna, enfim, um exímio operador da multidisciplinaridade.

Pode haver quem pondere que sua Teoria do Estado restou incompleta porque ele, precocemente, faleceu aos 42 anos de idade, deixando inacabado o seu livro "Teoria do Estado"2.

O Assistente de Hermann Heller, Gerhart Niemeyer, acentuou explicitamente a sua honradez intelectual e o seu rigor científico, enfatizando que esta díade jamais foi afetada por emoções, e constituiu o duplo pilar do reconhecido "crédito científico de Heller". 3

Desde logo, contudo, registre-se que mesmo sendo essa obra inconclusa, o que dela se publicou ${ }^{4}$ soma-se aos preciosos ensaios de Heller (alguns inéditos, outros já então publicados) reunidos sob o título "Escritos Políticos". Esses foram selecionados pelo Professor Antonio López Pina $^{5}$ e permitem juntamente com a obra inacabada acima mencionada - como o presente artigo pretende demonstrar - conhecer o núcleo nobre da Teoria de Estado do referido jurista alemão.

2 Trata-se de: HELLER, Hermann. Teoria do Estado. Tradução de Lycurgo Gomes da Motta. São Paulo: Mestre Jou,1968. Título original: Staatslehre.

3 NIEMEYER, Gerhart. Prólogo. In: HELLER, Hermann. Teoria do Estado. especialmente à p.8.

4 A Teoria do Estado de Hermann Heller acima referenciada foi publicada graças ao empenho de seu Assistente Gerhart NIEMEYER, que organizou a edição e nela inseriu o plano de capítulos que Heller tinha concebido para o seu inteiro teor.

5 Trata-se da obra: HELLER, Hermann. Escritos Políticos. Tradução de Salvador Gómez de Arteche. Prólogo e Seleção de Antonio López Pina. Madrid: Alianza Editorial, 1985. Esta obra, por sua feita é fruto do empenho do Prof. Dr. Antonio López Pina que a organizou. 
Tal núcleo compõe-se de aspectos nodais do pensamento helleriano que se pretende sejam identificados e desenhados, com boa precisão, por meio de categorias ${ }^{6}$ selecionadas, em objetivas perspectivas descritivas e analíticas, bem como em formulações informativas e doutrinárias do autor.

Para buscar esse desiderato, realizou-se uma Pesquisa Científica em cuja fase de investigação operou-se com o Método Dedutivo, eis que se partiu da premissa da existência efetiva de uma consistente Teoria de Estado proposta por Heller. Na fase de análise de dados, utilizou-se o Método Analítico. No relatório dos resultados, que é o presente artigo, trabalha-se com o Método Indutivo. As Técnicas utilizadas nas fases acima referidas foram: Técnica do Referente, da Categoria, do Conceito Operacional e da Pesquisa Bibliográfica. ${ }^{7}$

Em síntese, o objeto deste artigo é identificar o núcleo da Teoria do Estado concebida por Hermann Heller.

E os seus objetivos são:

(1) a descrição dos fundamentos e da concepção nuclear da referida Teoria por meio das categorias nucleares do pensamento helleriano, expresso em duas obras de sua autoria8;

(2) contribuir para a divulgação deste precioso material da epistemologia estatal de Heller, evidenciando a sua atualidade muito consistente.

\section{BREVE NOTÍCIA BIOGRÁFICA SOBRE HERMANN HELLER}

Hermann Heller nasceu em 17 de julho 1891 em Teschen, na Alemanha. Faleceu em 05 de novembro de 1933, em Madrid, onde se encontrava como refugiado para evitar sua prisão pelo Estado Alemão Nazista. Com a ascensão do nazismo ao poder na Alemanha, refugiou-se na Espanha, onde prosseguiu lecionando em Madrid até 1933, quando faleceu. ${ }^{10}$

Participou como voluntário do exército alemão na denominada Primeira Guerra Mundial, disto resultando grave doença cardíaca que o acompanhou por toda a vida e causou seu falecimento.

6 Categoria é "a palavra ou expressão estratégica à elaboração e/ou à expressão de uma idéia." Em PASOLD, Cesar Luiz . Metodologia da Pesquisa Jurídica. Teoria e Prática. Fpolis: EMais, 2018. p. 31. (negrito no original). Registre-se aqui ao leitor que o item nuclear do presente artigo é aquele no qual são trabalhadas as principais categorias de Hermann Heller, com as quais ele construiu a sua proposta de Teoria do Estado a partir principalmente de seus exercícios de Ciência Política e Teoria Política. Naquele item, é importante esclarecer, as categorias selecionadas estão grafadas em negrito sempre que são mencionadas em trechos que não se constituem em transcrições integrais. Algumas estão em negrito e com a letra inicial em maiúsculas e outras não. Assim será em respeito estrito à forma como estão grafadas nas obras de Heller.

7 Sobre Métodos e Técnicas vide: PASOLD, Cesar Luiz. Metodologia da Pesquisa Jurídica. Teoria e Prática. p. 89 a 101. (negrito no original). 8 Estamos nos referindo aos já citados: HELLER, Hermann. Teoria do Estado e HELLER, Hermann. Escritos Políticos.

9 Vide https://www.biografiasyvidas.com/biografia/h/heller_hermann.htm. Acesso em: 03 de fevereiro de 2019 e também http://biografias.wiki/ herman-heller/. Acesso em: 03 de fevereiro de 2019. No presente artigo, contudo, a biografia pessoal e intelectual apresentada foi composta também a partir de momentos especiais colhidos nas duas obras de Heller que sustentam este texto e já citadas retro. Vênia pela repetição, mas a fixação desta circunscrição foi nodal para a elaboração deste artigo e é base de sua lógica de conteúdo: HELLER, Hermann. Teoria do Estado e HELLER, Hermann. Escritos Políticos, ambos já citados.

Vide https://www.biografiasyvidas.com/biografia/h/heller_hermann.htm. Acesso em: 03 de fevereiro de 2019. 
Fruto de um relacionamento amoroso com Elisabeth Langgässer, teve a filha, Cordelia. Foi professor nas cidades de Kiel, Leipzig e Berlim, e no exílio lecionou em Madri.

São consideradas suas obras mais destacadas: A Soberania, de 1929; As Idéias Políticas Contemporâneas, de 1930; e Teoria do Estado ${ }^{11}$, publicada incompleta e postumamente, em 1934, sob a organização e fruto do empenho editorial de seu assistente, Gerhart Nemayer.

Merece registro especial, pela qualidade da seleção dos ensaios de Heller sobre temas estratégicos, o precioso trabalho de "recopilación" do Professor Antonio Lopez Pina já anteriormente referido ${ }^{12}$. Numa percepção panorâmica nas duas obras sustentadores do presente texto, percebe-se claramente que Heller interagiu com muitos autores clássicos e contemporâneos ou não dele, e não apenas de temas políticos e jurídicos. Como item biográfico destacado, diga-se que a cultura geral de Heller era impressionante, como o foi sua cultura jurídica.

A título de ilustração, elenca-se em lista não exaustiva, mas exemplificadora, iniciando pelos autores citados e trabalhados na obra Escritos Políticos ${ }^{13}$, os seguintes: Marx; Engels; Max Weber; Voltaire; Fichte; Bakunin; Georg Jellinek; Hans Kelsen; Pareto; Carl Schmitt; Nietzsche; Bergson; Croce; Jorge Sorel; Hegel; Thomas Mann; Spengler; Hobbes; Althusius; Sieyes; Lassale; Goethe; Otto Bauer; Friedrich Schiller; Otto von Bismark; Julian Borchardt; Oswald Spengler.

Na obra Teoria do Estado, destaca-se aqui que, ao início do capítulo intitulado "Objeto da Teoria do Estado"14, Heller arrola os autores (e respectivas obras consultadas) com os quais trabalhou para a sua composição: Pareto; Manheim; Max Weber; Stoltenberg e Koigen. No capítulo denominado "Método da Teoria do Estado": Dilthey (recomendando a edição completa deste autor publicada no México); M. Weber; Tillich; e Holstein ${ }^{15}$. No capítulo intitulado "A Realidade Social como Efetividade Humana", estão arrolados Scheler, Meusel e Korsch, este último na obra "Marxismus und Philosophie"16, de 1930. ${ }^{17}$ No capitulo denominado "A Sociedade Civil", destacam-se Lorenz V. Stein e Sombart, este com seu "Der moderne Kapitalismus"18. E para encerrar esta exemplificação, no Capítulo "Essência e Estrutura do Estado", especialmente em seu item "III. A FUNÇÃO SOCIAL DO ESTADO", alínea B sob título "Distinção da função política de outras funções sociais", opera, entre outros, com Spranger, Mannheim e C. Schmitt. ${ }^{19}$

\footnotetext{
11 Vide notas de rodapé números 2 e 3 , retro.

12 Vide: HELLER, Hermann. Escritos Políticos.

13 HELLER, Hermann. Escritos Políticos, p. 21 à p. 333. O elenco dos autores destacados encontra-se na ordem de referência na sequência dos ensaios constantes na obra. HELLER, Hermann. Teoria do Estado, p. 21. 


\section{A TEORIA DO ESTADO COM ÊNFASE PARA SUAS CONEXÕES COM A TEORIA POLÍTICA E A CIÊNCIA POLÍTICA NAS PROPOSTAS DE HELLER, RETRATADAS A PARTIR DE CATEGORIAS SELECIONADAS COMO ESTRATÉGICAS ${ }^{20}$}

Examinando os textos de Heller nas duas obras que aqui neste artigo são destacadas, encontram-se categorias cuja força lógica e semiológica é evidentemente ressaltada pelo autor, principalmente pela ênfase e importância nas suas frases e, pois, nos raciocínios por ele expostos. Tais categorias encontram-se fortes na lógica das suas propostas no campo da Teoria Política, da Ciência Política e, principalmente, Teoria do Estado, desenhadas com muita competência especialmente nas referidas duas obras. Sem que, com tal opção, esteja-se hierarquizando pelo critério de importância as duas obras de Heller eleitas para sustentar o presente texto, optou-se por principiar pelo relato dos resultados do exame efetuado em Escritos Políticos ${ }^{21}$, na qual predominam o desenho da Teoria Política helleriana e de sua forma de operar a Ciência Política.

Em seguida, serão objetivamente identificadas as categorias estratégicas do livro Teoria do Estado $^{22}$, no qual predomina o desenho da Teoria do Estado que ele propõe, sempre coerente com seus referentes básicos da Teoria Política e da Ciência Política.

Ressalte-se, portanto e desde logo aqui, ao bem da justiça, que Hermann Heller foi um profundo estudioso e exímio operador desta tríade: Teoria Política, Ciência Política e Teoria do Estado.

Sua Teoria Política, construída indutivamente, é um primoroso discurso doutrinário, sempre valorizador da Democracia.

A Ciência Política que manejou, alternando o método indutivo com o dedutivo e, em alguns momentos, com o dialético, na apreciação objetiva e responsavelmente crítica das relações de poder exercidas no âmbito da Sociedade sob a égide do Estado, é fruto de uma competente visão multidisciplinar, na qual se ressaltam especialmente a Sociologia e a História. Sobre esta última merece registro uma ressalva expressa de Heller, neste termo "A Teoria do Estado é Ciência de Estruturas e não Ciência Histórica."23

E a sua Teoria do Estado, elaborada dedutivamente, é uma proposta inteligente de concepção de Estado cuja vivência seja absolutamente comprometida com sua Função Social.

Examinando a obra intitulada "Escritos Políticos", inicia-se especificamente pelo ensaio intitulado "El Fascismo"24, para destacar a categoria Legitimidade.

Esclarece-se às leitoras e aos leitores que ao longo do presente item recorreu-se ao negrito para destacar as categorias mapeadas.

HELLER, Hermann. Escritos Políticos, especificamente da p.09 à. p. 333.

HELLER, Hermann. Teoria do Estado, especificamente da p. 21 à p. 327.

Vide HELLER, Hermann. Teoria do Estado. p. 71.

Vide p. 21 à p. 131, especialmente p. 57 e 59, do ensaio "Europa y el Fascismo", em HELLER, Hermann. Escritos Políticos. 
Ali ela é devidamente valorizada e trabalhada como sendo um "problema normativo", especialmente diante da dicotomia de um dever ser e de um ser, nas relações possíveis entre a norma e a vontade política. Heller invoca as ideias de imanência em Hobbes e Althusius, com ênfase ao Povo, que é literalmente a "categoria de sujeito de todo poder político".

Nesta linha, a categoria Democracia é também abordada, inclusive na perspectiva tenebrosa de sua possível superação, no plano da realidade, pelo fascismo em seus movimentos de massa.

Coerente com as suas convicções, Heller confere à Democracia o status de título da "Segunda Parte" desta obra, na qual resta evidente que para o autor há uma conexão absoluta entre sua concepção para Democracia e para a categoria Democracia Social.

A consequência é a coerente valorização da categoria Estado Social de Direito, na qual há espaço válido para um Socialismo Democrático.

Para tanto, a categoria singular e substantiva Socialismo é examinada em sua essência or meio de uma radiografia bem executada a partir das ideias mais puras de Karl Marx que, conforme Heller, foi movido pela sua "apasionada voluntad de justicia". ${ }^{25}$

Outra categoria com especial importância na lógica helleriana é Nação. Em suas pesquisas, Heller cuida de investigar e discorrer sobre um aspecto importante para a compreensão desta categoria, qual seja, a questão da divisão em raças, como ocorreu com a nação alemã. Neste aspecto, suas lições são especialmente preciosas ${ }^{26}$. No já referido anteriormente no capitulo denominado "A Sociedade Civil", Heller pondera que a "sociedade, enquanto conceito recíproco do Estado, é um fenômeno muito recente na história da Europa". Em sequência, ressalta a sua vinculação à plena evolução da "forma econômica capitalista" e, neste contexto, encontram-se três categorias devidamente valorizadas por ele: Sociedade Civil, Estado e Forma Econômica.

No ensaio sobre a Democracia, ele destaca a categoria Estado e a ela atribui um conceito operacional que classifica como "genérico". Nesta perspectiva, propõe que o Estado denote uma: "associação que assegura a operação conjunta e ordenada dos atos sociais em um território determinado."27 A categoria Estado de Direito, por sua vez, está trabalhada num item denominado "Estado de Derecho o Dictadura?", com ênfase para o que identifica como a degeneração da ideia de Estado de Direito, por consequência da modificação, em seus fundamentos, do significado "que

25 HELLER, Hermann. Escritos Políticos, p. 137. Em tradução livre do autor do presente artigo: "sua apaixonada vontade de justiça". Expressão que expõe o sentido contextual de Marx desejando a realização plena da justiça. Vide também preciosas lições sobre social democracia e socialismo em Lassale, nas p.183 e 184, principalmente.

26 Merece leitura especialmente atenta o item "La essência de la nación", que está da p. 148 à p. 155, quando os aspectos que tratam da "semelhança natural" e da "comunidade cultural" são objetivamente tratados para melhor compreensão da categoria Nação.

27 HELLER, Hermann. Escritos Políticos, p. 231. Tradução do autor do presente artigo de: "asociación que assegura la operación conjunta y ordenada de los actos sociales em um territorio determinado." 
ostenta o império da lei." ${ }^{28}$ E para encerrar este momento exemplificador de categorias fortes em Heller, especialmente nos seus "Escritos Polípticos", ressaltam-se duas - evidenciando a atualidade do autor - que as coloca em relação: a Ditadura e a Corrupção. Nesta dicotomia e sobre uma possível interação entra elas, afirma contundentemente: "Pode dizer-se disto que nenhum mito é tão mentiroso como aquele que diz que a Ditadura atua como extirpadora da corrupção". ${ }^{29}$

Pode-se ver agora algumas das categorias destacadas da obra Teoria do Estado ${ }^{30}$, na qual - coerentemente com suas convicções epistemológicas e metodológicas - Heller também opera a tríade: Teoria Política, Teoria do Estado e Ciência Política. E, registre-se, que o faz com a mesma qualidade com que se houve nos "Escritos Políticos".

Inicia-se o elenco exemplificador de categorias com a que denomina a obra, ou seja, Teoria do Estado, que ali é, por Heller, confundida inicialmente e de forma deliberada com a Ciência Política. Assim o faz no primeiro capítulo da obra referida, cujo título principal é "OBJETO DA TEORIA DO ESTADO", sendo o item inicial explicitamente denominado: "A Teoria do Estado como Ciência Política". Nesta perspectiva, diz: "A teoria do estado propõe-se investigar a específica realidade da vida estatal que nos rodeia". E mais: "Aspira a compreender o Estado na sua estrutura e função atuais, o seu devir histórico e as tendências de sua evolução". ${ }^{31}$

Portanto, duas constatações são possíveis.

A primeira: Heller está apresentando uma proposta de Teoria do Estado que não deseja que seja apenas teórica, porque a construiu operando descritiva, preditiva e prescritivamente. Relata a evolução (e em alguns momentos a involução) do Estado, em seguida prediz sobre seu melhor futuro e, por último, prescreve como construir - com segurança - este futuro!

A segunda: a sua Teoria do Estado se constrói em díade.

Isto significa que:

(1) a Teoria Política é somada à já referida visão multidisciplinar;

(2) a Ciência Política é muito valorizada nas suas duas perspectivas: conhecimento de realidade e predição/previsão, e, pois, acaba por não ser confundível com a Teoria do Estado. Neste segundo aspecto, merece que se ressalte que a sua Teoria do Estado não é idêntica à Ciência Política - mas

28 HELLER, Hermann. Escritos Políticos, p. 289.Tradução livre do autor do presente artigo de: "que ostenta el imperio de la leye.".

29 HELLER, Hermann. Escritos Políticos, p. 294. Em traduções livres do autor do presente artigo, respectivamente de: "?Estado de Derecho o Dictadura?". E de: "Puede decir se por ello que ningún mito es tan mendaz como el de que la Dictadura actúe como extirpadora de la corrupción."

30 HELLER, Hermann. Teoria do Estado.

31 HELLER, Hermann. Teoria do Estado. p.21. 
sim as duas são interativas! Mais adiante, identifica-a como sendo "em todos os seus aspectos, uma ciência sociológica da realidade." ${ }^{\text {32 }}$

E para atender tais pretensões, com que categorias Heller constrói sua Teoria do Estado, que mesmo inacabada por causa de seu falecimento precoce, já tem conteúdos suficientes para um excelente draft? ${ }^{33}$

A primeira das categorias é Estado (sem adjetivos!) que:

(1) ele é uma formação social, que precisa ser distinguida "restritivamente" em dois pontos de vista - tanto objetivamente quanto metodologicamente - de qualquer outra "estrutura de sentido";

(2) ele não é um "espírito objetivo"; (3) ele é "uma forma de vida humano-social, vida em forma e forma que nasce da vida". ${ }^{4}$

Um dos momentos mais significativos da Teoria do Estado de Heller é a sua proposta de que "de certa forma" há uma deontologia estatal, conforme a qual aquele que pretender

...descobrir o ser do Estado, terá por força que levar em conta as comunidades de vontade de valores que se atualizam no presente do Estado, e além disso referir-se ao seu futuro. ${ }^{35}$

Assim o é porque o Estado é um ente tipicamente de "acontecimento humano" do qual o sujeito "somos nós mesmos", sempre sob a tutela do princípio de que conhecer a realidade política e valorizá-la são dois aspectos "profundamente unidos". ${ }^{36}$

Por isso, também há que se atribuir importância à realidade social dos grupos humanos, cujas bases são os elementos qualitativos que eles detêm e de se constituírem "em estruturas capazes de decisão e ação". ${ }^{37}$

Outro aspecto do perfil básico do Estado para Heller é que jamais é possível atribuir-se ao Estado a condição de exercer exclusivamente a função econômica. Assim deve ser porque o homem, enquanto viver em sociedade - ou seja, com outros homens -, tem diversas funções sociais. ${ }^{38}$

Neste diapasão, Heller fundamenta a sua Teoria de Estado também numa possibilidade radical relacionada com o poder econômico, que merece transcrição literal, assim:

\footnotetext{
32 HELLER, Hermann. Teoria do Estado. p.71.

33 Alerta-se o leitor para o fato de que aqui poderão ocorrer repetições de categorias já ressaltadas no exame que foi efetuado na obra "Escritos Políticos", retro, no presente artigo. E assim se faz porque a repetição é necessária à melhor compreensão do Pensamento de Heller sobre Estado.

34 HELLER, Hermann. Teoria do Estado. p 65.

35 HELLER, Hermann. Teoria do Estado. p 79.

36 HELLER, Hermann. Teoria do Estado. p.81.

37 HELLER, Hermann. Teoria do Estado. p.137.

38 HELLER, Hermann. Teoria do Estado. p.135 e 131, respectivamente.
} 
Ou o poder do Estado há de conseguir a possibilidade de emancipar-se politicamente das influências econômicas privadas mediante uma sólida base de poder econômico próprio, ou a luta dos dirigentes da economia há de obter, pelo menos, o êxito prévio de que seja eliminada em seu benefício a legislação democrática. ${ }^{39}$

Enfatize-se que a categoria povo, por sua vez, é muito especialmente trabalhada na lógica helleriana. Em sua Teoria do Estado, o povo40 é examinado como "formação natural" e como "formação cultural". Ali o autor relata os resultados de suas pesquisas tendo como pressuposto o que classifica como "extraordinária variedade de acepções em que é usada a palavra 'povo'(Volk)", e suas consequências na forma de "tantas e tão perigosas confusões".

Aqui se torna necessário destacar que Heller, especialmente nas duas obras que sustentam o presente artigo, evidencia a sua consciência lúcida sobre a importância de certas categorias e com seus conceitos operacionais devidamente estabelecidos, para a construção de sólidas propostas teóricas e práticas no campo da Teoria do Estado.

Ao tratar do povo como formação natural, há uma abordagem sobre a categoria raça. A premissa é a de que para cada "raça física", há a correspondência com uma "alma racial" especial. E entre elas não há uma dialética nem uma dicotomia, mas sim a existência de especificas maneiras de reagir na dimensão estatal ou "conteúdos mentais específicos" no plano político. ${ }^{41}$

Uma das teses de Heller é a que denomina povo cultural, isto é, o povo como "realidade operante e operada". E nele, o pertencer a um povo implica numa conexão "espiritual tradicional", que em sendo atualizada "de modo vivo, dentro de si mesmo", implica em representação dele, com consciência de suas "excelências" e de seus "defeitos", o que o transforma em "conexão de vontade política". 42 Alerta de forma bem contundente para os perigos da confusão entre os conceitos de povo e nação, se soberania do povo, com soberania nacional, com vontade estatal. São categorias distintas, em alguns casos, sutilmente, mas o são. Considera este erro como característico da Teoria do Estado "do século passado"43.

Outra categoria também estratégica para Heller é a opinião pública, que ele retira de uma posição de exclusividade na Ciência Política e a traz, com força, para a Teoria do Estado.

39 HELLER, Hermann. Teoria do Estado. p.172. Esta proposta de Heller merece cotejo com as considerações de MYRDAL, Gunnar. O Estado do Futuro. Tradução de Affonso Blacheyre. Rio de Janeiro: Zahar,1980.Título Original: sem menção no exemplar utilizado. Em especial, p.77 e seguintes. Myrdal vincula o Estado do Bem-Estar Democrático explicitamente com compromisso de "metas de desenvolvimento econômico, pleno emprego, igualdade de oportunidades para jovens", entre outros. Também é recomendável a leitura do item 13, no qual é tratada a "legitimação da hegemonia do capital", em GRAU, Eros. A Ordem Econômica na Constituição de 1988. 19. ed. rev. atual. São Paulo: Malheiros, 2018, p. 41.

40 Vide o item "3. As condições da atividade estatal que se relacionam com o povo "em suas alíneas A e B, em: HELLER, Hermann. Teoria do Estado. p. 183 à p. 203.

HELLER, Hermann. Teoria do Estado. p.185.

HELLER, Hermann. Teoria do Estado. p.197.

HELLER, Hermann. Teoria do Estado. p. 199. Ali estava a se referir ao Século XVIII e, em seguida, critica Rosseau por ter conferido ao "povo" - que não tinha condições de ser representado - a possibilidade de ser identificado com a "volonté générale do Estado". 
De modo objetivo localiza historicamente a "doutrina da opinion publique" como fruto pioneiro da "escola fisiocrática", na qual Mercier de la Riviere, autor monarquista, se baseou para defender que a legitimidade do Rei de um País está não nele (o Rei), mas sim na opinião pública que sustenta e apoia a Monarquia.

Contudo, Heller pontua que "modernamente" a opinião pública tem seus fundamentos em princípios e doutrinas democráticos, provocando um "status político", conforme o qual se estabelece entre a autoridade e os súditos "uma opinião pública comum sob a forma de uma comunidade de vontade e de valores".

Aqui, deve-se alertar que o advérbio "modernamente", empregado pelo autor, refere-se à primeira metade do anos 1900, período no qual se destacam as Constituições: Mexicana (1917) ${ }^{44}$ e de Weimar (1919). Ambas possuem características democráticas fortes e com o início da consagração de dispositivos da Lei Maior comprometidos com a Função Social do Estado. ${ }^{45}$

Um dos aspectos interessantes da análise de Heller sobre a opinião pública é o momento em que revela sua crítica ácida e contundente contra o liberalismo.

Segundo ele:

O liberalismo atribui geralmente à opinião pública uma capacidade política de agir de que em realidade carece, e sobrestima excessivamente a sua força efetiva perante os meios organizados do poder do estado. ${ }^{46}$

Outra categoria fundamental para a Teoria de Estado conforme Heller é o Direito expressamente referido como o positivado e não à ideia e às teorias do direito -, que é "condição da unidade estatal", porque atua na realidade histórica e social. Propõe, nessa linha, que a realidade social funcione como "ponto de partida para determinar o conceito de direito positivo". Estabelece base sólida para a Produção do Direito. Interessante registrar, também, que no item em que ele se dedica ao Direito como condição da Unidade Estatal, ele trata com destaque do Jurista, cuidando daquele que denomina "jurista dogmático, ou mais exatamente o jurista judicial, que só se interessa pela aplicação de preceitos jurídicos da jurisdição civil e penal" ${ }^{47}$

44 Para conhecer o teor da Constituição Mexicana de 1917, vide: CONSTITUCIÓN POLÍTICA DE LOS ESTADOS UNIDOS MEXICANOS. http:// www.ordenjuridico.gob.mx/Constitucion/cn16.pdf. Acesso em: 20/02/19. Sobre seu conteúdo inovador, recomenda-se: COMPARATO, Fábio. A Constituição Mexicana de 1917. http://www.dhnet.org.br/educar/redeedh/anthist/mex 1917.htm. Acesso em 20/02/19;BONAVIDES, Paulo. O Pioneirismo da Constituição Mexicana de 1917. https://archivos.juridicas.unam.mx/www/bjv/libros/9/4430/6.pdf. Acesso em: 20/02/19. ROBL FILHO, Ilton Norberto. Constituição mexicana de 1917 e os avanços dos direitos sociais no Brasil. http://www.scielo.org.mx/scielo. php?script=sci_arttext\&pid=S1405-91932017000100361. Acesso em: 20/02/2019.

45 As Constituições Mexicana (1917) e de Weimar-Alemanha (1919) pela sua forma e pelo seu conteúdo indicam fortemente que foram compostas sob influência da Teoria de Hermann Heller.

46 HELLER, Hermann. Teoria do Estado. p. 218.

47 Vide a categoria Direito trabalhada integralmente por HELLER, Hermann. Teoria do Estado. Da p. 221 à p. 239. 
Na III parte da obra intitulada "Essência e Estrutura do Estado", no item 1, dedica-se àquela que é, sem dúvida, a categoria mais importante para sua Teoria: a Função Social do Estado.

Trata dela inicialmente sob a perspectiva de sua "legalidade peculiar", receitando para a Teoria do Estado que ela "pode e deve indagar o sentido de Estado cuja expressão é a sua função social, a sua ação social objetiva". Ali, refere-se a "grandes teóricos", destacando nominalmente Aristóteles e Hobbes pelo que chama de "interpretação objetiva" do Estado, e não a "interpretação subjetivapsicológica" que não aceita e o diz reiteradamente. ${ }^{48}$

A linha de raciocínio construtiva da Função Social encetada por Heller tem como básica a definição de Goethe: "A função é a existência pensada em atividade". Coerentemente com esta premissa, Heller pontua que a "função do estado nos é necessariamente dada por uma situação cultural e natural". 49

Heller considera a política como uma das funções sociais, mas insiste em sua caracterização peculiar que a diferencia das outras saídas que com elas interaja. Pondera que o conceito do que é político tem uma amplitude muito maior do que o conceito de Estado. Preocupa-se com a proliferação de significados para a palavra política - fenômeno que já estava presente nas produções de Teoria Política e Ciência Política. O seu conceito operacional, "no mais alto e exemplar sentido", para a categoria política é: "a organização e atuação autônoma da cooperação social em um território". ${ }^{50}$

Pondera, noutra dimensão, que "nem toda atividade do Estado é atividade política". E, enfim, considera o poder militar como condição "iniludível" para a existência do poder estatal como um todo.

Contudo, antes desta constatação, é fortemente contundente em sua opinião:

Um poder militar que não se subordine ao encargo de organizar e atuar a cooperação social em um território, não é mais do que uma quadrilha de bandoleiros". ${ }^{51}$

Na sequência, cuida da relação entre as categorias Estado e Igreja, sendo peremptório que o Estado é, "por sua função, um poder secular". 52

48 HELLER, Hermann. Teoria do Estado. p. 243.

49 HELLER, Hermann. Teoria do Estado. p. 244 e 245.

50 HELLER, Hermann. Teoria do Estado. p. 247. Merece aqui uma referência elogiosa o hábito científico de Hermann Heller de zelar para que o seu leitor tenha ciência dos conceitos operacionais que adota para as categorias estratégicas às suas formulações, logo que põe a delas tratar. Neste aspecto, pode-se dizer que Heller é aristotélico.

51 A transcrição literal encontra-se em: HELLER, Hermann. Teoria do Estado. p. 251, inserida no contexto do item "Distinção da função política de outras funções sociais" que vai da p. 246 à p. 252.

HELLER, Hermann. Teoria do Estado. p. 252 à p. 254. 
No item seguinte, trabalha a relação entre as categorias "Estado e a economia"53, revelando objetivamente os resultados de suas pesquisas quanto às percepções sobre economia nos pensamentos capitalista, marxista e socialista, esta última na perspectiva de Saint Simon. ${ }^{54}$

Estabelece pelo menos dois princípios teórico-práticos (como costumava ser o seu estilo) que merecem destaque: "A razão de Estado e a razão econômica sempre foram coisas diferentes." 55 .

Assim: "A necessidade de uma regulação extra econômica da economia pelo Estado nasce da necessidade de uma ordenação estatal de caráter geral referida essencialmente um determinado território". ${ }^{56}$ Retornando à categoria nuclear, registre-se que Heller possui uma peculiar percepção da categoria função, quando especificada em espécies, como nucleares à sua teoria. Nessa classificação tipológica, refere-se destacadamente a três: a função estatal, a função jurídica e a função social. ${ }^{57}$

Esta última, ao que se percebe na leitura dos textos de Heller, torna-se a mais importante para sua construção teórica e proposição prática para o Estado em sua relação com a Sociedade que o mantém. Mais especialmente, ainda, em sua Teoria do Estado, a Função Social é tida e valorizada como essência determinante da Estrutura e da Dinâmica Estatal.

Esta circunstância, na opinião de Heller, constitui-se num dos principais pilares para a sua constatação de que qualquer organização e, pois, também o Estado "organiza, de maneira imediata", atividades e não opiniões. Essas últimas acabam sendo compostas na dinâmica da vida em Sociedade. ${ }^{58}$ Importante ressaltar aqui uma das suas melhores lições da Teoria Política que subsidia fortemente a sua Teoria do Estado, é sua advertência para que não se confunda o "núcleo de poder que realiza positivamente o poder estatal, com o próprio Estado". Heller afasta peremptoriamente este "sofisma" que provoca as "inadmissíveis concepções que confundem o estado com o seu Governo e o poder do Estado com o poder do governo".

Merece especial registo, também, a importância da categoria organização que se encontra presente ao longo de toda a sua Teoria do Estado e, e por isto mesmo, muito presente nas duas obras apreciadas para a composição deste artigo. É importante reiterar que Heller trabalha com essa categoria desde os primeiros momentos da sua construção de proposta teórico-prática para um Estado que se comprometa com o Bem Comum e busque efetivamente a sua concretização.

$53 \quad$ HELLER, Hermann. Teoria do Estado. p. 254 à p. 259.

54 Sobre o socialismo proposto por Saint Simon, classificado como um dos autores clássicos do "socialismo utópico" (ao lado de Robert Owen e Charles Fourier), recomenda-se o texto objetivo de CARVALHO, Leandro. Socialismo Utópico. https://www.historiadomundo.com.br/idadecontemporanea/socialismo-utopico.htm. Acesso em: 21/02/2019.

HELLER, Hermann. Teoria do Estado. p. 257.

HELLER, Hermann. Teoria do Estado. p. 258.

HELLER, Hermann. Teoria do Estado. Em especial, p. 261.

Vide destacadamente HELLER, Hermann. Teoria do Estado. p. 279. 
Contudo, na sua obra nuclear - "Teoria do Estado" -, o seu conceito operacional para ela somente é explicitado quase ao final do texto composto da obra, nestes termos:

Entendemos por organização a ação concreta de dar forma à cooperação dos indivíduos e grupos que participam no todo, mediante a supra-, sub- e coordenação dos mesmos. ${ }^{59}$

Outra categoria que merece valorização maior de Heller ao final da obra acima referida é Estado de Direito, à qual antepõe o adjetivo "moderno". Esta espécie de Estado é compreendida por Heller como capaz de cumprir o "postulado de uma continuidade normativa, histórica e sistemática", sob a preocupação de que "fosse sempre possível e eficaz". 60

No que concerne às categorias Constituição e Constituição do Estado, ainda que constando em diversos momentos das obras objeto do presente artigo, optou-se por enfocar especialmente a forma peculiar com que Heller as diferencia em momento muito adiantado da "Teoria do Estado".

Recorre-se aqui, mais uma vez, às transcrições literais, necessárias para preservar íntegro o pensamento do autor, em momento no qual se entra em risco de desrespeito ao pensamento original, se for utilizada a paráfrase. Assim:

Até aqui consideramos a Constituição do Estado, em um sentido, como formação da situação política total; [...]. Temos distinguido a Constituição do Estado, como estrutura de efetividade política, do seu correlato objetivado no campo jurídico como Constituição jurídica objetivada.

Mais adiante:

A exigência de uma Constituição no sentido de uma ordenação e unidade planificadas do Estado, só se pode compreender em oposição à tradicional, e neste sentido, irracional estrutura de poder dos grupos políticos da Idade Média. ${ }^{61}$

Enfim:

[...] uma Constituição precisa, para ser constituição, isto é, algo mais que uma relação factícia ${ }^{62}$ e instável de dominação, para valer como ordenação, de uma justificativa segundo princípios éticos de direito ${ }^{63 .}{ }^{64}$

Lembre-se de que a obra "Teoria do Estado", vênia pela repetição, ficou inacabada por Heller, que foi vitimado por grave doença cardíaca ${ }^{65}$.

59 HELLER, Hermann. Teoria do Estado. p. 295.

60 HELLER, Hermann. Teoria do Estado. p.315.

61 HELLER, Hermann. Teoria do Estado. p. 317 e 319.

62 Ou seja: produzida artificialmente.

63 Isto é, dotada de legitimidade. Para reflexões quanto a Heller, vide a categoria legitimidade em: FARIA, José Eduardo. Poder e Legitimidade. São Paulo: Perspectiva, 1978.

64 HELLER, Hermann. Teoria do Estado. p. 327

65 Em NIEMEYER, Gerhart. Prólogo. In: HELLER, Hermann. Teoria do Estado. p. 7 à p. 17. ( datado de julho de 1934). 
Contudo, como já enfatizado, o seu assistente, Gerhart Niemeyer, editou-a, construindo um emocionante, mas não menos científico, "Prólogo" e um "Apêndice". Neste último, revela a sequência capitular que Heller iria preencher com conteúdo, tecendo alguns comentários - acrescidos de transcrições literais de apontamentos de Heller - que revelam o quanto Niemeyer conhecia o pensamento do seu mestre!

Uma leitura atenta desse Apêndice demonstra que as categorias nodais para Heller, que se destacou até aqui, prosseguiriam sustentando e/ou avançando para outras categorias nos capítulos cujos conteúdos não chegou a redigir. ${ }^{66}$

Esta consistência das categorias e de sua zelosa interconexão contribui para dar forte solidez a uma qualidade fundamental da Teoria de Heller, que é a sua atualidade. Isto é, ela esteve e prossegue disponível para sustentar válidos argumentos em defesa de um espectro sempre maior da Função Social do Estado na contemporaneidade, com suas nuances e peculiaridades.

Em homenagem à Heller, pode-se afirmar que uma consistente Função Social do Estado Contemporâneo traduz-se no compromisso do Estado, em parceria com a Sociedade, dedicar-se prioritariamente a pelo menos a quatro segmentos: Meio Ambiente; Saúde; Educação; e Segurança Pública. ${ }^{67}$ No que diz respeito especialmente à relação do Estado com o Meio Ambiente a partir da Teoria de Estado de Hermann Heller, merece menção destacada o artigo científico intitulado "A Necessária Evolução do Estado de Direito Social Teorizado por Hermann Heller ao Estado de Direito Socioambiental Diante da Crise Ambiental na Sociedade de Riscos". O referido texto é de autoria de CRUZ, Paulo Márcio; FARIA, Daniela Lopes; e ITO, Christian Normitsu ${ }^{68}$.

Nesse artigo, quatro categorias são notáveis: (1) Estado de Direito Social; (2) Estado Socioambiental; (3) Crise Ambiental; e (4) Sociedade de Riscos, sendo a primeira a com maior vinculação à Teoria de Heller, e, pois, básica para a lógica fundamental das demais.

Em síntese, o referido artigo valoriza devidamente Hermann Heller e sua Teoria, o que evidencia o quanto a contribuição científica de Heller é importante e serve efetivamente aos estudiosos do Interesse Coletivo na atualidade!

$66 \quad$ NIEMEYER, Gerhart. Apêndice. In: HELLER, Hermann. Teoria do Estado. p. 329 à p. 338.

67 Vide, por exemplo: PASOLD, Cesar Luiz. Função Social do Estado Contemporâneo. 4. ed. rev. amp. Itajaí: UNIVALI, 2013, em especial p. 51 à p. 64, e p. 66 à p. 76. Acesso gratuito ao inteiro teor da obra e-book: http://siaiapp28.univali.br/LstFree.aspx

68 Vide: CRUZ, Paulo Márcio; FARIA, Daniela Lopes; ITO, Christian Normitsu. A Necessária Evolução do Estado de Direito Social Teorizado por Hermann Heller ao Estado de Direito Socioambiental Diante da Crise Ambiental na Sociedade de Riscos. ANIMA: Revista Eletrônica do Curso de Direito das Faculdades OPET. Curitiba PR - Brasil. Ano VIII, nº 14, jan./jun. 2016. 


\section{CONSIDERAÇÕES FINAIS}

Ao longo de todo o presente artigo, e mais especialmente em seu item 2, acima encerrado, procurou-se descrever a base lógica da Teoria do Estado proposta por Hermann Heller.

Utilizaram-se, como elementos nucleares para compor o respectivo draft, as categorias com as quais o autor alemão construiu sua Teoria do Estado, destacadamente em duas de suas obras com justiça devidamente homenageadas no presente artigo.

Toda a leitura e releitura atenta de Heller que se efetuou para compor o presente texto ora em encerramento sustenta, com convicção, quatro constatações:

(1) a indubitável competência científica de Hermann Heller, com destaque especial para sua biografia intelectual, plena do conhecimento de autores de significativa qualidade;

(2) o seu comprometimento permanente com a mais elevada Ética na Pesquisa;

(3) a sua especial habilidade em realizar a fase de investigação de dados utilizando o método indutivo e - raramente, mas com competência - o dedutivo; em seguida, a competente análise dos dados colhidos, com igual maestria, preponderantemente por meio do método dialético; este aprumo metodológico confere consistência científica à sua obra; e,

(4) a atualidade de suas propostas e reflexões, nas três dimensões Teoria Política, Ciência Política e Teoria do Estado, com ênfase para a terceira.

Enfim, com as categorias selecionadas, explicitadas de forma objetiva e o mais fielmente possível ao pensamento expresso diretamente por Hermann Heller, pretende-se, nesse texto, ter estabelecido, descritivamente e com alguns aportes analíticos nodais, o esquema básico da sua excelente Teoria do Estado.

Vênia pela insistência, mas Heller a construiu solidamente, a partir de suas percepções como Cientista Político e das lições que acumulou e ampliou em Teoria Política.

Contudo, o mais importante é que ele, generosamente, a compartilhou com seus leitores e alunos, com elevada qualidade e na quantidade máxima que lhe foi possibilitada pelo curto período em que viveu.

\section{REFERÊNCIAS DAS FONTES CITADAS}

BONAVIDES, Paulo. O Pioneirismo da Constituição Mexicana de 1917. In: https://archivos.juridicas.unam.mx/www/bjv/ libros/9/4430/6.pdf 
BRASIL. Constituição da República Federativa do Brasil-1988. In: http://www2.camara.leg.br/atividade-legislativa/ legislacao/Constituicoes_Brasileiras/constituicao1988.html

CARVALHO, Leandro. Socialismo Utópico. In: https://www.historiadomundo.com.br/idade-contemporanea/socialismoutopico.htm

COMPARATO, Fábio. A Constituição Mexicana de 1917. In: http://www.dhnet.org.br/educar/redeedh/anthist/mex1917. $\mathrm{htm}$

CRUZ, Paulo Márcio; FARIA, Daniela Lopes; ITO, Christian Normitsu. A Necessária Evolução do Estado de Direito Social Teorizado por Hermann Heller ao Estado de Direito Socioambiental Diante da Crise Ambiental na Sociedade de Riscos. ANIMA: Revista Eletrônica do Curso de Direito das Faculdades OPET. Curitiba PR - Brasil. Ano VIII, n 14, jan./jun. 2016. ESTADOS UNIDOS MEXICANOS. CONSTITUCIÓN POLÍTICA DE LOS ESTADOS UNIDOS MEXICANOS. In: http://www. ordenjuridico.gob.mx/Constitucion/cn16.pdf

FARIA, José Eduardo. Poder e Legitimidade. São Paulo: Perspectiva, 1978.

GRAU, Eros. A Ordem Econômica na Constituição de 1988. 19. ed. rev. atual. São Paulo: Malheiros, 2018.

HELLER, Hermann. Escritos Políticos. Tradução de Salvador Gómez de Arteche. Prólogo e Seleção de Antonio López Pina. Madrid: Alianza Editorial, 1985.

HELLER, Hermann. Teoria do Estado. Tradução de Lycurgo Gomes da Motta. São Paulo: Mestre Jou,1968. Título original: Staatslehre.

MYRDAL, Gunnar. O Estado do Futuro. Tradução de Affonso Blacheyre. Rio de Janeiro: Zahar,1980.Título Original: sem menção no exemplar utilizado.

NIEMEYER, Gerhart. Prólogo. In: HELLER, Hermann. Teoria do Estado. Tradução de Lycurgo Gomes da Motta. São Paulo: Mestre Jou,1968. Título original: Staatslehre. p.7 à p. 17.

NIEMEYER, Gerhart. Apêndice. In HELLER, Hermann. Teoria do Estado. Tradução de Lycurgo Gomes da Motta. São Paulo: Mestre Jou, 1968. Título original : Staatslehre . p. 329 à p. 338

PASOLD, Cesar Luiz . Metodologia da Pesquisa Jurídica. Teoria e Prática. 14. ed. rev. atual. amp. Fpolis: EMais, 2018.

PASOLD, Cesar Luiz. Função Social do Estado Contemporâneo. 4. ed. rev. amp. Itajaí/SC: UNIVALI, 2013. E-book- gratuito: http://siaiapp28.univali.br/LstFree.aspx. 